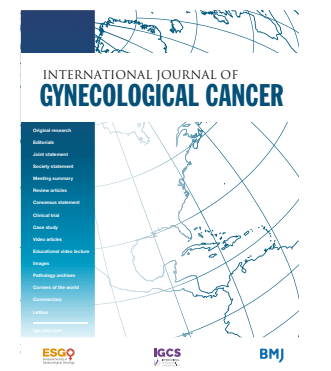

${ }^{1}$ Kaluga Regional Cancer Center, Kaluga, Russian Federation ${ }^{2}$ Gynecologic Oncology, N.N. Blokhin National Medical Research Center of Oncology of the Ministry of Health of the Russian Federation, Moscow, Russian Federation

\section{Correspondence to} Dr Sergey Skugarev, Kaluga Regional Cancer Center, Kaluga 248002, Russian Federation; skugarevsa@gmail.com

Accepted 19 April 2021 Published Online First 12 May 2021

\section{Right extraperitoneal approach for laparoscopic paracaval bulky lymph node dissection for endometrial cancer}

Sergey Skugarev (D) , ${ }^{1}$ Igor Nikolaev, ${ }^{1}$ Igor Kudryavtsev (D) , ${ }^{1}$ Alexey Shevchuk ${ }^{2}$
A 65-year-old patient presented with endometrial adenocarcinoma G2, myometrial invasion $>50 \%$, and enlarged precaval $(6 \times 3 \mathrm{~cm})$ and retrocaval $(3 \times 1.5 \mathrm{~cm})$ lymph nodes up to the level of the renal veins on computed tomography. Clinical stage was cT1bN2M0, IIIC2.

According to the Russian guidelines on the treatment of uterine malignancy, surgery is the treatment of choice for these patients. ${ }^{1}$ Total hysterectomy with pelvic and para-aortic lymphadenectomy was planned.

Left extraperitoneal laparoscopic para-aortic lymphadenectomy for cervical cancer was first described by Dargent et al. The feasibility and advantages of this approach as a staging procedure for gynecologic malignant tumors have been shown in different studies. ${ }^{2} 3$ However, the standard left extraperitoneal approach provides limited access to the paracaval and retrocaval areas, so the right extraperitoneal approach was used for this patient.

Video 1 describes the benefits and feasibility of dissection of precaval and retrocaval bulky nodes

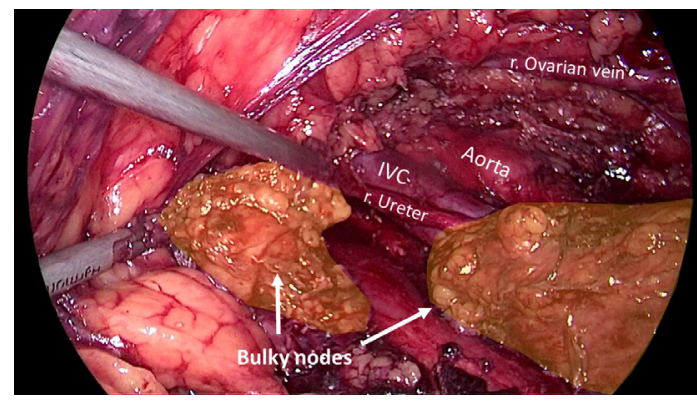

Figure 1 Completely removed precaval and retrocaval bulky lymph nodes.

by the right extraperitoneal laparoscopic approach. The right extraperitoneal access was created in the same way as from the left side. ${ }^{4}$ After placement of a $10 \mathrm{~mm}$ balloon trocar, the pneumo-extraperitoneum was created; $5 \mathrm{~mm}$ and $12 \mathrm{~mm}$ trocars were then placed on the right anterior axillary line and the right mid-clavicular line.

The main part of the surgery was performed with ultrasonic scissors. Using blunt dissection and

\title{
GYNECOLOGICAL CANCER
}

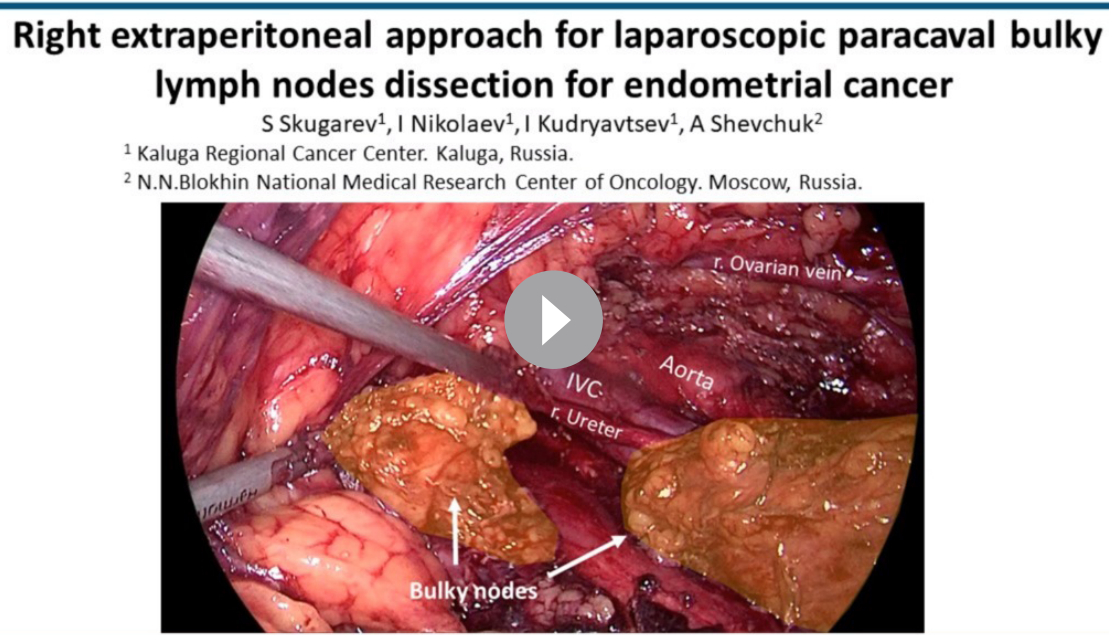

@IJGConline

To cite: Skugarev S, Nikolaev I, Kudryavtsev I, et al. Int J Gynecol Cancer

2021;31:1088-1089.

(C) IGCS and ESGO 2021. No commercial re-use. See rights and permissions. Published by BMJ. 
sliding movements, enlarged nodes were carefully separated from the vena cava and the common iliac vein. Retrocaval nodes were separated from the posterior wall of the vena cava first and then from the surrounding tissue. The completely removed bulky nodes are shown in Figure 1.

The final pathologic evaluation confirmed metastasis in the para-aortic and pelvic nodes from both sides.

The main limitation of this approach is the insufficient access to the left aortic lymph nodes.

The surgery was carried out in the Gynecologic Oncology department of Kaluga Regional Cancer Center, Russian Federation.

Contributors All authors conceived the study concept and advised on the surgical procedure. All authors participated in writing the manuscript and approved the final version. All authors agree to be accountable for all aspects of the work in ensuring that questions related to the accuracy or integrity of any part of the work are appropriately investigated and resolved.

Funding The authors have not declared a specific grant for this research from any funding agency in the public, commercial or not-for-profit sectors.

Competing interests None declared.
Patient consent for publication Not required.

Provenance and peer review Not commissioned; externally peer reviewed.

Data availability statement There are no data in this work.

ORCID iDs

Sergey Skugarev http://orcid.org/0000-0002-0521-8207

Igor Kudryavtsev http://orcid.org/0000-0002-3811-3612

\section{REFERENCES}

1 Nechushkina V, Kolomiec L, Kravec O. Practice guidelines for treatment of uterine cancer and uterine sarcomas. In: Malignant tumours: practice guidelines. RUSSCO, 2020.

2 Vázquez-Vicente D, Fernández Del Bas B, García Villayzán J, et al. Retroperitoneal laparoscopic para-aortic lymphadenectomy in paraaortic staging of locally advanced cervical cancer. J Minim Invasive Gynecol 2018;25:1142-3.

3 Díaz-Feijoo B, Franco S, Torné A, et al. Implications of extraperitoneal paraaortic lymphadenectomy to the left renal vein in locally advanced cervical cancer. A Spanish multicenter study. Gynecol Oncol 2020;158:287-93.

4 Boria Alegre F, Cabanes M, Hernández Gutiérrez A, et al. How to develop an appropriate extraperitoneal para-aortic space. Int $J$ Gynecol Cancer 2019;29. 